\title{
Genetic diversity and differentiation in Camellia reticulata (Theaceae) polyploid complex revealed by ISSR and ploidy
}

\author{
B.-Y. Wang and Z.-Y. Ruan \\ Kunming, P.R. China \\ Corresponding author: B.-Y. Wang \\ E-mail:wbykm@yahoo.com.cn \\ Genet. Mol. Res. 11 (1): 503-511 (2012) \\ Received August 3, 2011 \\ Accepted January 9, 2012 \\ Published March 6, 2012 \\ DOI http://dx.doi.org/10.4238/2012.March.6.3
}

Research Institute of Resource Insects, Chinese Academy of Forestry,

\begin{abstract}
Camellia reticulata is a well-known ornamental and oil plant that is endemic to southwest China. This species shows three cell ploidies, i.e., diploidy, tetraploidy and hexaploidy. We made the first investigation of genetic diversity and differentiation of natural populations of $C$. reticulata, and 114 individuals from 6 populations were sampled. Cytogeography results showed that ploidy is invariable within populations and evenly distributed. A relatively high level of genetic diversity was found in $C$. reticulata, both at the species level ( $\mathrm{PPB}=88.89 \% ; \mathrm{H}=0.2809 ; \mathrm{I}=0.4278)$ and at the population level (mean PPB $=42.13 \%$; mean $\mathrm{H}=0.14$; mean $\mathrm{I}=0.21$ ). We found a relatively low degree of differentiation among ploidies $\left(G_{\mathrm{ST}}=\right.$ 0.2384 ; $\mathrm{AMOVA}=10.26 \%$ ) and a relatively high degree of differentiation among populations $\left(G_{\mathrm{CS}}=0.3807\right.$; AMOVA $\left.=48.75 \%\right)$. The high genetic diversity can be explained by its biological character, wide distribution and ploidies, and the special genetic structure can be ascribed to polyploid origin from hybridization with different Camellia spp. This information will be useful for the introduction, conservation and further studies of $C$. reticulata and related species.
\end{abstract}

Key words: Camellia reticulata; Genetic diversity; ISSR; Ploidies 


\section{INTRODUCTION}

Camellia reticulata Lindl is an evergreen shrub or arbor with a natural distribution in Yunnan and the region southwest of Sichuan, China (Ming, 2000). It was first identified in 1827 based on a cultivar from Tengchong, Yunnan, and its relatives in the field were found in the 1940s; the specimens were hexaploid (Ming, 1998). The diploidy and tetraploidy of $C$. reticulata were discovered in 1994 and 1997, respectively (Xia et al., 1994; Gu, 1997). These 3 cell ploidies are the currently established ploidies in C. reticulata. Although some cytology studies have been carried out on C. reticulata (Kondo et al., 1986; Xiao et al., 1993; Xia et al., 1994), cytogeography in C. reticulata has not been examined, and whether different ploidies occur within a population is still unknown.

C. reticulata is not only valued as a flowering ornamental but also as an oil plant. It has been cultivated in China for more than 1300 years. It is famous worldwide for its large flowers, bright and charming colors, multiple cultivars, and long flowering season. Its seeds, widely cultivated in the southwest of China, have high oil content, and its oil is rich in unsaturated fatty acids, vitamin E, and other physiologically active substances. Despite its great value, the numbers and areas of natural populations have decreased rapidly because of overharvesting and habitat destruction. Genetic diversity and a natural distribution pattern are significant for the use and conservation of $C$. reticulata, but studies on $C$. reticulata genetic diversity and its pattern of natural populations have not yet been performed.

Polyploid complexes are prevalent in herbage, but wood polyploid complexes are seldom seen. C. reticulata is one of them. Origin, differentiation, and distribution are basic aspects in the understanding of a species, but these characteristics are complicated in $C$. reticulata, not only because it is a polyploid complex but also because it is sympatric with some related species. Studies have provided evidence of the origin of its polyploid populations in Panzhihua, Sichuan, China (Gu and Xiao, 2003; Liu and Gu, 2011), but no information is available about other polyploid populations. Studying genetic differentiation among ploidies and populations provides an overall understanding of $C$. reticulata and information from which to speculate about the course of its origin, differentiation, and distribution.

Intersimple sequence repeat (ISSR) is a polymerase chain reaction (PCR)-based technique that amplifies sequences between adjacent, inversely oriented microsatellites using an SSR-containing primer (Zietkiewicz et al., 1994). The strategy is especially attractive because it avoids the need to carry out the costly cloning and sequencing inherent in the original microsatellite-based approach. Moreover, locus-specific probes and microsatellite-containing sequences of interest can be developed by isolating and cloning or reamplifying individual bands (Wu et al., 1994; Zietkiewicz et al., 1994). ISSR has been profitably used for studies of genetic diversity in various plants at the species and population levels (Kumar, 2002; Nybom, 2004; Luo et al., 2010; Wang, 2010). Because ISSR primers are longer, they may show greater repeatability and stability of map position in the genome in comparisons of closely related individuals (Zietkiewicz et al., 1994).

In this study, we investigate the chromosome number and the genetic diversity and pattern of $C$. reticulata in its natural range. The aims of this study were to clarify the chromosome number (ploidies) of $C$. reticulata populations, estimate genetic diversity at both the species and the population level, analyze the genetic differentiation among ploidies and populations of $C$. reticulata, and discuss the implications of our study on the conservation, use, and management of this valuable resource. 


\section{MATERIAL AND METHODS}

Six populations were sampled from within their natural distributions in southwest China (Table 1; Figure 1). Fresh leaves were collected and dried with silica in a resealable plastic bag for approximately 2 weeks, and genomic DNA was extracted and isolated from the dry leaves according to a modified cetyltrimethylammonium bromide procedure (Wang, 2003).

Table 1. Information on the Camellia reticulata populations studied.

\begin{tabular}{llccc}
\hline Population name & Location & Latitude $(\mathrm{N})$ & Longitude $(\mathrm{E})$ & Height $(\mathrm{m})$ \\
\hline Tengchong & Yunnan, Tengchong & 25.11 & 98.28 & 2005 \\
Yanbian & Sichuan, Yanbian & 27.12 & 101.28 & 2443 \\
Huidong & Sichuan, Huidong & 26.77 & 102.69 & 2250 \\
Xichang & Sichuan, Xichang & 27.73 & 102.35 & 2197 \\
Fuming & Yunnan, Fuming & 25.53 & 102.62 & 1627 \\
Yunxian & Yunnan, Yunxian & 24.30 & 100.14 & 2087 \\
\hline
\end{tabular}

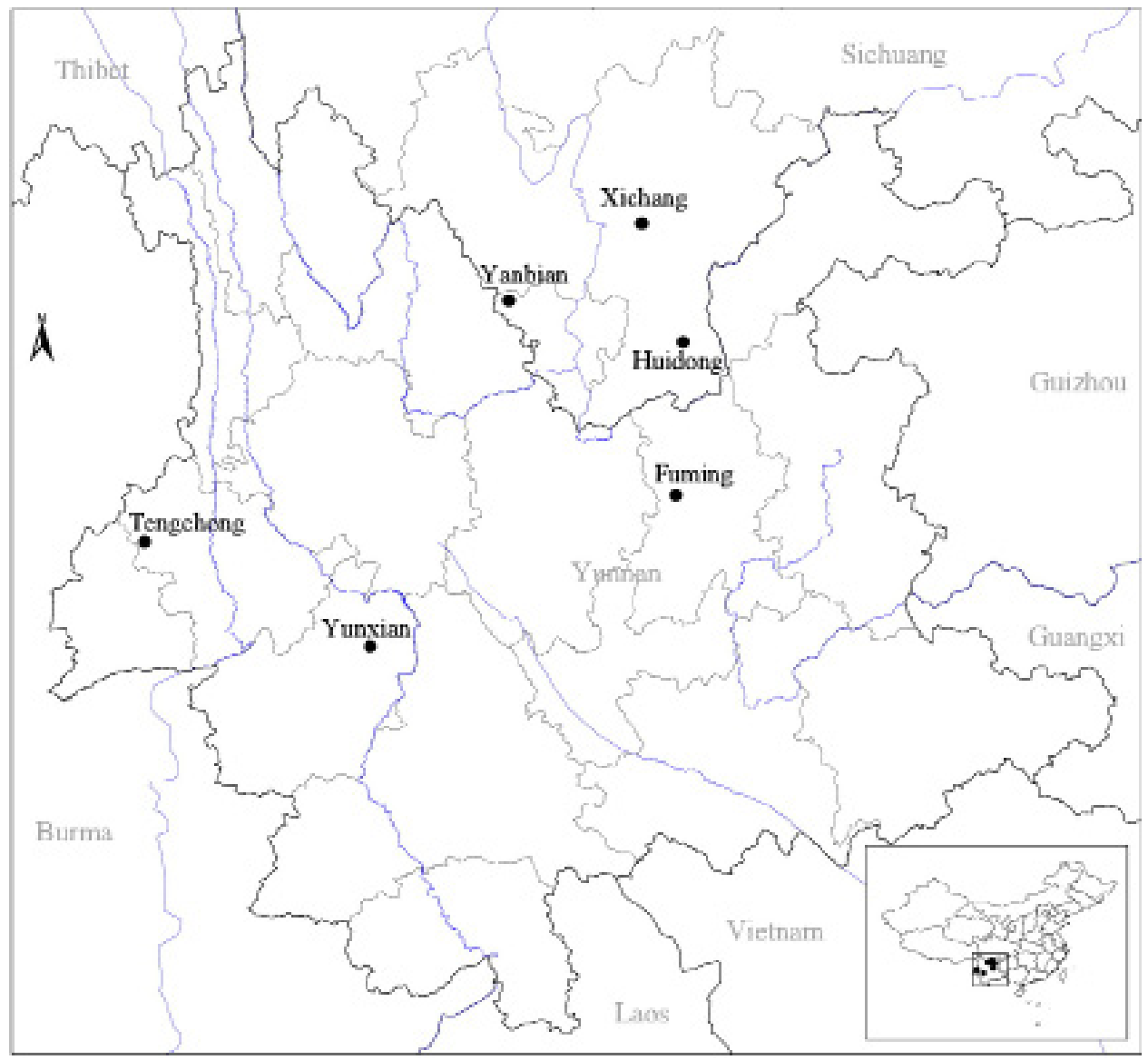

Figure 1. Locations of the Camellia reticulata populations studied. 
Fourteen polymorphic primers were selected from 144 ISSR primers, which were synthesized by the Shanghai Biotechnology Company. PCR amplification was carried out in a $20-\mu \mathrm{L}$ solution containing $10 \mathrm{ng}$ DNA, $10 \mathrm{nmol}$ deoxynucleotide triphosphates, $6 \mathrm{nmol} \mathrm{MgCl}_{2}, 24 \mathrm{pmol}$ primer, $2 \mathrm{U}$ DNA Tag polymerase, $2 \mu \mathrm{L}$ buffer (Fermentas), and sterile water to volume. Optimal amplification conditions for ISSR were 1 cycle of $5 \mathrm{~min}$ at $94^{\circ} \mathrm{C}$ (initial denaturation) followed by 35 cycles of $45 \mathrm{~s}$ at $94^{\circ} \mathrm{C}$ (denaturation), $45 \mathrm{~s}$ at annealing temperature (the annealing temperatures for the primers appear in Table 2), and $100 \mathrm{~s}$ at $72^{\circ} \mathrm{C}$ (extension). A final step of $7 \mathrm{~min}$ at $72^{\circ} \mathrm{C}$ ensured full extension of all amplified products. PCR products were separated on a $1.6 \%$ agarose gel, stained with ethidium bromide, and visualized using ultraviolet transillumination.

\begin{tabular}{|c|c|c|c|}
\hline Sequence (5'-3') & Annealing temperature $\left({ }^{\circ} \mathrm{C}\right)$ & Sequence (5'-3') & Annealing temperature $\left({ }^{\circ} \mathrm{C}\right)$ \\
\hline ACACACACACACACACYT & 49 & СТССТССТССТССТС & 51 \\
\hline CACACACACACACAGT & 47 & GGAGAGGAGAGGAGA & 49 \\
\hline CACACACACACACAGG & 50 & GGGGTGGGGTGGGGT & 57 \\
\hline GAGAGAGAGAGACC & 45 & AGAGGGAGAGGGAGAGGG & 57 \\
\hline AGAGAGAGAGAGAGAGYT & 49 & HVHTGTTGTTGTTGTTGT & 45 \\
\hline AGAGAGAGAGAGAGAGYC & 51 & BDVCAGCAGCAGCAGCAG & 56 \\
\hline GTGTGTGTGTGTGTGTYC & 51 & DBBCAGCAGCAGCAGCAG & 56 \\
\hline
\end{tabular}

Where $\mathrm{Y}=\mathrm{C}+\mathrm{T}, \mathrm{H}=\mathrm{A}+\mathrm{C}+\mathrm{T}, \mathrm{V}=\mathrm{A}+\mathrm{C}+\mathrm{G}, \mathrm{B}=\mathrm{C}+\mathrm{G}+\mathrm{T}$, and $\mathrm{D}=\mathrm{A}+\mathrm{G}+\mathrm{T}$.

Only ISSR bands that could be unequivocally scored were counted in the analysis. As dominant markers, amplified DNA marker bands were scored in a binary manner as either present (1) or absent (0) and entered into a binary data matrix. Genetic diversity was measured according to the percentage of polymorphic bands (PPB), Nei's genetic diversity (Nei, 1973), and the Shannon diversity index. These were calculated using POPGENE v1.32 (Yeh et al., 2000). The nonparametric analysis of molecular variance program v1.55 (Excoffier et al., 1992) was used to describe genetic structure among the populations. An unweighted pairgroup method with arithmetic means dendrogram was constructed with Molecular Evolutionary Genetics Analysis 3 based on the matrix of genetic distance calculated with POPGENE v1.32. The Mantel test was performed using NTSYSpc 2.1e to test for a correlation between genetic distance and geographic distance between populations.

To check the chromosome number, fruits were collected from 10 individuals in each population and brought to the laboratory in a dilly bag. Seedlings from the seeds that were cultivated and growing root tips were treated according to Gu and Sun (1997). The chromosomes were counted with a compound microscope.

\section{RESULTS}

\section{Cytogeography} in Table 3.

The chromosome number within populations was invariable, and the results are shown

\section{Genetic diversity}

Fourteen ISSR primers were used in 6 populations of C. reticulata, generating 108 
bands ranging in size from 200 to $2000 \mathrm{bp}$. Five to nine loci were scored per primer. At the species level, the PPB, Nei's genetic diversity, and the Shannon diversity index were $88.89 \%$, 0.2809 , and 0.4278 , respectively. Within the populations, the PPB ranged from 25.00 to $52.78 \%$, Nei's genetic diversity between the populations ranged from 0.0981 to 0.1611 , and the Shannon diversity index between the populations ranged from 0.1429 to 0.2426 (see Table 3).

Table 3. Genetic diversity and ploidy of Camellia reticulata.
\begin{tabular}{llcccc}
\hline Population & $\mathrm{N}$ & $\mathrm{H}$ & $\mathrm{I}$ & $\mathrm{PPB}(\%)$ & Chromosome number \\
\hline Tengchong & 20 & $0.1518(0.2003)$ & $0.2247(0.2873)$ & 41.67 & 90 \\
Yanbian & 19 & $0.1438(0.1998)$ & $0.2126(0.2852)$ & 39.81 & 30 \\
Huidong & 20 & $0.1358(0.1795)$ & $0.2112(0.2584)$ & 52.78 & 60 \\
Xichang & 16 & $0.1336(0.1892)$ & $0.2009(0.2725)$ & 40.74 & 60 \\
Fuming & 20 & $0.1611(0.1997)$ & $0.2426(0.2828)$ & 52.78 & 90 \\
Yunxian & 19 & $0.0981(0.1823)$ & $0.1429(0.2603)$ & 25.00 & 90 \\
Total & 114 & $0.2809(0.1703)$ & $0.4278(0.2280)$ & 88.89 & \\
\hline
\end{tabular}

$\mathrm{H}=$ Nei's genetic diversity; $\mathrm{I}$ = Shannon diversity index; PPB = percentage of polymorphic bands.

\section{Differentiation}

The coefficient of differentiation among ploidies $\left(G_{\mathrm{ST}}\right)$ was 0.2384 , and that among populations within ploidies $\left(G_{\mathrm{CS}}\right)$ was 0.3807 (Table 4$)$. Analysis of molecular variance showed a genetic differentiation among the ploidies and among the populations within ploidies in C. reticulata. Of the total genetic diversity, $10.26 \%$ resided among ploidies, $48.75 \%$ resided among the populations within ploidies, and the rest $(40.99 \%)$ resided among individuals within populations (Table 5). Indirect estimates of the level of gene flow $\left(N_{\mathrm{m}}\right)$ between ploidies and populations were calculated to be 0.8134 and 1.5977 individuals per generation, respectively.

Table 4. Coefficient of differentiation for Camellia reticulata.
\begin{tabular}{lccccccc}
\hline Parameter & $H_{\mathrm{T}}$ & $H_{\mathrm{C}}$ & $H_{\mathrm{S}}$ & $G_{\mathrm{ST}}$ & $G_{\mathrm{CS}}$ & $N_{\mathrm{m}}\left(G_{\mathrm{ST}}\right)$ & $N_{\mathrm{m}}\left(G_{\mathrm{CS}}\right)$ \\
\hline Mean & 0.2912 & 0.1374 & 0.2218 & 0.2384 & 0.3807 & 0.8134 & 1.5977 \\
SD & 0.0292 & 0.0112 & 0.0208 & & & & \\
\hline
\end{tabular}

Table 5. Analysis of molecular variance (AMOVA) for six populations of Camellia reticulata.
\begin{tabular}{lrrrrrrrc} 
Source of variation & d.f. & SS & MS & VC & \% of total variance & P \\
\hline Among ploidies & 2 & 493.4 & 246.7 & 1.83 & $10.26 \%$ & 0.15 \\
Among populations within ploidies & 3 & 481.9 & 160.6 & 8.69 & $48.75 \%$ & $<0.001$ \\
Within populations & 108 & 788.9 & 7.3 & 7.3 & $40.99 \%$ & $<0.001$ \\
\hline
\end{tabular}

d.f. $=$ degrees of freedom; $\mathrm{SS}=$ sum of square; $\mathrm{MS}=$ mean square; $\mathrm{VC}=$ variance component.

Genetic distance between populations ranged from 0.0769 to 0.4042 , and geographic distance between populations ranged from 111.81 to $498.39 \mathrm{~km}$ (Table 6). The Mantel test, which shows the coefficient of correlation between genetic and geographic distances was neither high $(\mathrm{R}=0.20735)$ nor significant $(\mathrm{P}=0.2443)$. The relationships among the 6 populations are shown in a dendrogram based on Nei's genetic distance, and the populations with different ploidies were not divided into different clusters (Figure 2). 


\begin{tabular}{|c|c|c|c|c|c|c|}
\hline & Tengchong & Yanbian & Huidong & Xichang & Fuming & Yunxian \\
\hline Tengchong & & 372.71 & 477.42 & 498.39 & 440.41 & 209.55 \\
\hline Yanbian & 0.3153 & & 146.19 & 125.49 & 223.58 & 330.12 \\
\hline Huidong & 0.2239 & 0.2830 & & 111.81 & 135.66 & 374.43 \\
\hline Xichang & 0.1953 & 0.3547 & 0.1232 & & 247.83 & 440.92 \\
\hline Fuming & 0.1691 & 0.2650 & 0.0913 & 0.0769 & & 222.69 \\
\hline Yunxian & 0.3803 & 0.4042 & 0.2445 & 0.2815 & 0.2623 & \\
\hline
\end{tabular}

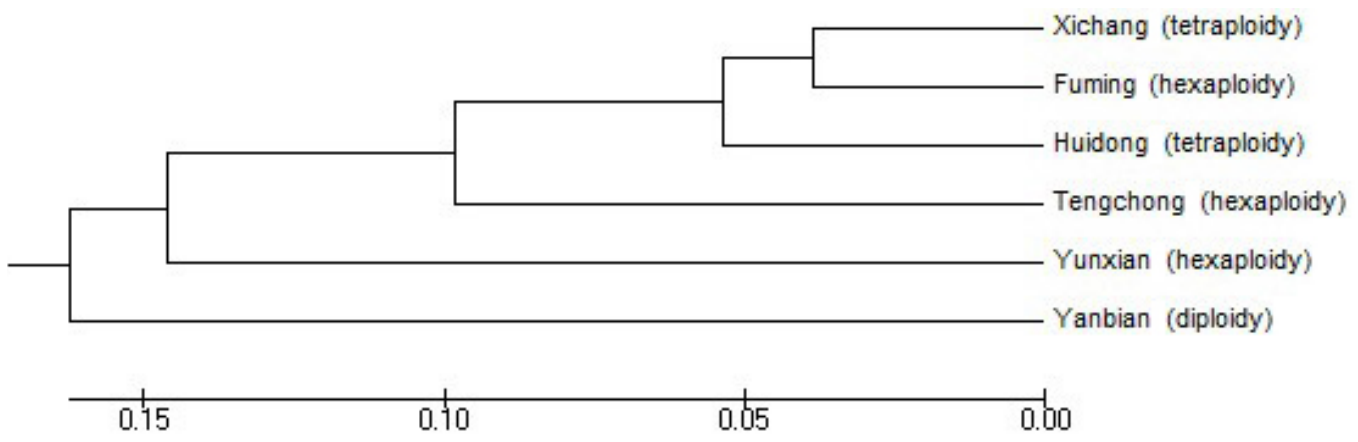

Figure 2. UPGMA dendrogram based on Nei's genetic distance.

\section{DISCUSSION}

Although morphologic character varied within populations, the chromosome number was invariable within populations. Our results, together with those of earlier studies (Kondo et al., 1986; Gu, 1997; Ming, 2000), have clarified the distribution of ploidies in C. reticulata. The diploidy live in only one location in Yanbian, Sichuan, and the tetraploidy live in a narrow zone adjacent to the diploidy. The hexaploidy occupy the rest of the distribution. The regular distribution of ploidies may be related to the course of polyploidization and spread; when a species spreads, it has a greater chance of having higher ploidy, and higher ploidy can spread further because it may have greater adaptive capability.

With polymorphic and monomorphic loci used for calculation, genetic diversity in $C$. reticulata was not only higher than the mean level in plants but also higher than that of relative species in Camellia. The mean PPB of plant species determined by RAPD markers is $62 \%$ (Zou et al., 2001). At the species level, the mean PPBs in gymnosperms, dicotyledons, and monocotyledons are 70.9, 44.8, and 59.2\%, respectively, and at the population level, the mean PPBs in gymnosperms, dicotyledons, and monocotyledons are 57.7, 29.0, and 40.3\%, respectively (Hamrick and Godt, 1989). In Camellia japonica, allozyme analysis revealed a PPB of $81 \%$ and an $\mathrm{H}$ of 0.322 at the species level; mean PPB was $62-69 \%$, and mean $\mathrm{H}$ was 0.245 0.265 at the population level (Wendel and Parks, 1985; Chung and Kang, 1996; Chung and Chung, 2000). In Camellia nitidissima, RAPD and amplified fragment length polymorphism analysis revealed that PPB was $78.1-72.5 \%$ and $\mathrm{H}$ was $0.2698-0.2444$ at the species level; mean PPB was 32.3-37.3\% and mean $\mathrm{H}$ was $0.1069-0.1288$ at the population level (Tang et al., 2006). In Camellia sinensis ISSR, RAPD, and allozyme analysis showed a PPB of 57.4-84\% 
at the species level; mean PPB was 21.4-50\%, and mean I was 0.229 at the population level (Kaundun et al., 2000; Kumar, 2002; Chen et al., 2005; Thomas et al., 2006). In the present study, PPB was $88.89 \%$, H was 0.2809 , and I was 0.4278 at the species level; mean PPB was $42.12 \%$, mean $\mathrm{H}$ was 0.1373 , and I was 0.2058 at population level.

A high level of genetic diversity may be the result of the common character of Camellia species as well as the individuated character of $C$. reticulata, because the genetic diversity of species in Camellia is higher than the mean level of genetic diversity in other plants, and the genetic diversity of $C$. reticulata is higher than that of other Camellia species. A high level of genetic diversity may also be related to life form and mating system. Long-lived woody and outcrossing species have levels of genetic diversity that are higher than those of other life forms and species with different mating systems (Hamrick et al., 1992; Hamrick and Godt, 1996). Species in Camellia are all long-lived woody plants with outcrossing mating systems (Ming, 2000). Camellia reticulata has more genetic diversity than other Camellia species, which can be explained by its large geographic range and complex ploidies. Camellia reticulata is distributed from Yunnan to Sichuan Provinces in the southwest of China, and its distribution is wider than that of most Camellia species (Ming, 1998). Species with wider distribution tended to be more genetically diverse (Casiva et al., 2002). There are 3 cell ploidies in C. reticulata, and some polyploidy populations have been shown to originate through hybridization (Hamrick and Godt, 1996). Introgression of other Camellia species has also promoted genetic diversity in $C$. reticulata.

Most of the variation in C. reticulata occurs among populations $\left(G_{\mathrm{CS}}=0.3807 ; 48.75 \%\right.$ variation lies among populations within ploidies), and very little variation occurs among ploi$\operatorname{dies}\left(G_{\mathrm{ST}}=0.2384 ; 10.26 \%\right.$ variation lies among ploidies). This result can be explained by the origin of polyploidy. The distribution area of $C$. reticulata overlaps with other Camellia species such as $C$. saluenensis, $C$. pitardii var. potardii, $C$. pitardii var. variabilis, $C$. mairei var. mairei, C. mairei var. lapidea, C. mairei var. velutina, and C. yunnanensis (Ming, 1998). Some polyploidy populations of $C$. reticulata have been shown to originate through hybridization, and the local Camellia species participated in the origin of the polyploidy (Gu and Xiao, 2003; Liu and Gu, 2011). Camellia reticulata has overlapped different Camellia species in different locations, so different ploidy populations and populations with the same ploidy may have different genetic composition. Therefore, the main genetic differentiation is among populations but not among ploidies, and the populations do not cluster according to ploidies. Genetic distance is also not decided by geographic distance.

Although the genetic diversity is rich at the species level in C. reticulata, the genetic differentiation existed not only among ploidies but also among populations with the same ploidy, and some populations lacked members and genetic diversity. For example, the Yanbian population, the only recorded diploidy population in C. reticulata, was considered to be the ancestor of $C$. reticulata, and no more than 50 individuals remain. The Yunxian population, one of the hexaploidy populations, differs from the other hexaploidy populations in its large plant body, flowers, and fruits; only 19 individuals remain, and their genetic diversity is much lower than that of other populations. These 2 populations should be protected first. In conclusion, this study provides data on the cytogeography, genetic diversity and its distribution, differentiation among ploidies, and populations of $C$. reticulata and contributes to an overall understanding of the living status of the species. We expect this study to be helpful in resource conservation, introduction, and further studies of $C$. reticulata and related species. 


\section{ACKNOWLEDGMENTS}

The research was funded by the Science and Technology Ministry and State Forestry Administration, China (\#2009BADB1B01), and the Yunnan Provincial Science and Technology Department (\#2009CD149).

\section{REFERENCES}

Casiva PV, Saidman BO, Vilardi JC and Cialdella AM (2002). First comparative phenetic studies of Argentinean species of Acacia (Fabaceae), using morphometric, isozymal, and RAPD approaches. Am. J. Bot. 89: 843-853.

Chen J, Wang P, Xia Y, Xu M, et al. (2005). Genetic diversity and differentiation of Camellia sinensis L. (cultivated tea) and its wild relatives in Yunnan province of China, revealed by morphology, biochemistry and allozyme studies. Genet. Resour. Crop Evol. 52: 41-52.

Chung MG and Kang SS (1996). Genetic variation within and among populations of Camellia japonica (Theaceae) in Korea. Can. J. Forest. Res. 26: 537-542.

Chung MG and Chung MY (2000). Levels and partitioning of genetic diversity of Camellia japonica (Theaceae) in Korea and Japan. Silvae Genet. 49: 119-124.

Excoffier L, Smouse PE and Quattro JM (1992). Analysis of molecular variance inferred from metric distances among DNA haplotypes: application to human mitochondrial DNA restriction data. Genetics 131: 479-491.

Gu ZJ (1997). The discovery of tetraploid Camellia reticulata and its implication in studies on the origin of this species. Acta Phytotaxon. Sin. 35: 107-116.

Gu ZJ and Sun XF (1997). A karyomorphological study of seventeen species of Chinese camellis. Acta Bot. Yunanica 19: 159-170.

Gu ZJ and Xiao H (2003). Physical mapping of the 18S-26S rDNA by fluorescent in situ hybridization (FISH) in Camellia reticulata polyploid complex (Theaceae). Plant Sci. 164: 279-285.

Hamrick JL and Godt MJW (1989). Allozyme Diversity in Plant Species. In: Plant Population Genetics, Breeding and Genetic Resources (Brown AHD, Clegg MT, Kahler AL and Weir BS, eds.). Sinauer, Sunderland, 43-63.

Hamrick JL and Godt MJW (1996). Effects of life history traits on genetic diversity in plant species. Phil. Trans. R. Soc. Lond. B 351: 1291-1298.

Hamrick JL, Godt MJW and Sherman-Broyles SL (1992). Factors influencing levels of genetic diversity in woody plant species. New Forest. 6: 95-124.

Kaundun SS, Zhyvoloup A and Park YG (2000). Evaluation of the genetic diversity among elite tea (Camellia sinensis var. sinensis) accessions using RAPD markers. Euphytica 115: 7-16.

Kondo K, Gu ZJ, Na HY and Xia L (1986). A cytological study of Camellia reticulata and its closely related species in Yunnan, China. Kromosomo II 43-44: 1405-1419.

Kumar MT (2002). Assessment of genetic diversity of tea (Camellia sinensis (L.) O. Kuntze) by inter-simple sequence repeat polymerase chain reaction. Euphytica 128: 307-315.

Liu LQ and Gu ZJ (2011). Genomic in situ hybridization identifies genome donors of Camellia reticulata (Theaceae). Plant Sci. 180: 554-559.

Luo ZB, Zhuang GQ, Ma DW and Chen F (2010). Genetic diversity of Pogonatherum paniceum (Lam.) Hack in Southwest China revealed by ISSR. Afr. J. Biotechnol. 9: 1416-1422.

Ming TL (1998). The Classification, Differentiation and Distribution of the Genus Camellia Sect. Camellia. Acta Bot. Yunanica 20: 127-148.

Ming TL (2000). Monograph of the Genus Camellia. Yunnan Science and Technology Press, Kunming.

Nei M (1973). Analysis of gene diversity in subdivided populations. P. Natl. Acad. Sci. U. S. A. 70: 3321-3323.

Nybom H (2004). Comparison of different nuclear DNA markers for estimating intraspecific genetic diversity in plants. Mol. Ecol. 13: 1143-1155.

Tang S, Bin X, Wang L and Zhong Y (2006). Genetic diversity and population structure of yellow camellia (Camellia nitidissima) in China as revealed by RAPD and AFLP markers. Biochem. Genet. 44: 449-461.

Thomas J, Vijayan D, Joshi SD, Joseph LS, et al. (2006). Genetic integrity of somaclonal variants in tea (Camellia sinensis (L.) O. Kuntze) as revealed by inter simple sequence repeats. J. Biotechnol. 123: 149-154.

Wang BY (2003). The Population Genetics in Paeonia delevayi. Master's thesis, Yunnan University, Kunming.

Wang G (2010). Genetic diversity of ancient male ginkgo trees by ISSR analysis. J. Beijing Forest. U. 32: 39-45.

Wendel JF and Parks CR (1985). Genetic diversity and population structure in Camellia japonica L. (Theaceae). Am. J. 
Bot. $72:$ 52-65.

Wu KS, Jones R, Danneberger L and Scolnik PA (1994). Detection of microsatellite polymorphisms without cloning. Nucleic Acids Res. 22: 3257-3258.

Xia LF, Gu ZJ, Wang ZL, Xiao TJ, et al. (1994). Dawn on the origin of Camellia reticulata - the new discovery of its wild diploid in Jinshajiang valley. Acta Bot. Yunanica 16: 255-262.

Xiao TJ, Gu ZJ and Xia LF (1993). A study of meiosis of 9 species in genus Camellia. Acta Bot. Sin. 15: 167-172.

Yeh FC, Yang R, Boyle TJ, Ye Z, et al (2000). PopGene32, Microsoft Windows-Based Freeware for Population Genetic Analysis. Version 1.32. Molecular Biology and Biotechnology Centre, University of Alberta, Edmonton.

Zietkiewicz E, Rafalski A and Labuda D (1994). Genome fingerprinting by simple sequence repeat (SSR)-anchored polymerase chain reaction amplification. Genomics 20: 176-183.

Zou YQ, Ge S and Wang XD (2001). Molecular Marker in Plant Systematics and Evolution. Science Press, Beijing, 112. 